\title{
Research on the Construction of Performance Evaluation System of Enterprise Process Reengineering
}

\author{
Bingfeng Liu and Ningning Yan \\ School of Management and Economics, Jingdezhen Ceramic Institute, Jiangxi Province, China \\ txcf2000@163.com
}

\begin{abstract}
Keywords: Business process reengineering (BPR); Performance evaluation; Data envelopment analysis; Performance evaluation system; Construction of performance
\end{abstract}

\begin{abstract}
Business process reengineering was first formed in the United States, it combines a variety of advanced management experience and ideas, including total quality management theory, lean production theory, etc. The theory of BPR has been improved with the help of advanced experience, and the core competence is the goal. Process reengineering is one of the important means for enterprises to cope with the fierce competition, but the poor performance of BPR has become one of the main obstacles to the development of enterprises and the construction of enterprise informatization. This paper probes into the connotation of process reengineering, process reengineering and its evaluation, analyzes the reasons and conditions of process reengineering, and constructs the performance index system and its cross evaluation model.
\end{abstract}

\section{Introduction}

In the United States scholars on the company's production process research produced originally thought of BPR practice, found no change in the company's business operating procedures, operating procedures to improve the work or business restructuring will greatly improve the efficiency of the company.

First, define the concept of the process. As the name implies, it refers to a series of programs that are needed to complete the task. These programs have the time difference. The business process is the operation of the company in order to achieve the strategic objectives and tasks of the development of a series of operating procedures, in the course of the operation of the process of value added and customer needs to meet. A process is a combination of a series of inputs that produce the value of the customer's needs. All operating companies are in order to obtain benefits, long-term development. In order to meet the needs of the customer, all the work procedures are designed to meet the needs of customers. The significance of these workflows is to convert the company's inputs into outputs. Therefore, the company's operating procedures are all in the scope of business processes, including raw material procurement procedures, raw materials processing procedures, product sales procedures, product improvement procedures, etc..

Two is to define the concept of process reengineering. Process reengineering is actually the reflection and improvement of a series of procedures, not to overthrow the company for the development and hinder the efficiency of the process, develop new operating procedures, the company has been a radical reform in reducing the cost and improve the efficiency of customer service, service and production speed etc.. The core of the book is to put forward four main reform ideas: basic, thorough, significant and process. The basic re thinking is the reflection and consideration of the most basic problems in the operation of the company. For example, choose the things you want to do, the things you do, the reasons for doing things, the best way to do things, the time to do things, etc.. With these problems, we can improve the company's operating process, improve work efficiency, increase operating profit, and provide an inexhaustible motive force for the future development of the company. A thorough redesign is based on a fundamental rethinking. After repeated thinking of the basic problems of the company and the problems found in the operation process, we can put forward some practical and effective measures to solve the specific problems. This is one of the processes necessary to reform the company's operating procedures. Significant change is one of the characteristics of reform of company operating procedures, 
it is not a subtle change and improvement, the company is working on the nature of the program, completely changed, can greatly improve work efficiency, reduce production costs and so on, which bring to the company's revenue is huge. Process refers to the content and object of corporate reform. The reform of the company's operating procedures is in fact the reform of the company's work processes, the composition of each step of the composition of all the work process. All of the business process is all about creating customer value need to be expanded, so in the process of re improvement, protection of customer value need to constantly create and value-added, to continue to build the company's core competitiveness in the fierce competition.

However, after entering the twenty-first Century, the company's business has undergone great changes, so the research on the concept of business process reengineering is constantly changing. Hame argues that there is no radical, fundamental improvement in the improvement of the work program, because the company is in a constantly changing environment. Therefore, the reform should always exist, is a continuous work.

\section{Process Reengineering Performance and its Connotation}

Process Reengineering Performance. The word "performance" is originally derived from the English "Performance", which indicates the effectiveness of a work in a certain period of time. The results include performance and results. From the performance of this concept, the process reengineering performance comes from two aspects, namely, the operating process and acceptance results. The operation process refers to the process reengineering, the strategic goal of the company limited resources of the Achieve Inc; refers to the acceptance of the results, the effect of the recycling process, whether to complete the company's strategic target, whether to achieve customer needs value etc..

Performance Evaluation of Process Reengineering. From different angles, the understanding of performance evaluation is also different. From the company's strategic objectives, performance is a measure of the completion of its objectives; from the company's business management, performance is the premise of the company's management and the core elements. Evans believes that performance evaluation is a very important process in the company's business management, reasonable performance evaluation can promote the scientific management of the company, optimize the allocation of resources, and build the core competitiveness. Maskell put forward the 7 characteristics of performance evaluation: the company's development strategy for non financial indicators; rating; can be used in any situation; more flexible, can make corresponding improvement according to the actual situation; convenient operation; effective feedback from the company's operations and business operation; its main function is to promote rapid the development of the company. This study is based on the strategic objectives of the company, the performance is a measure of the degree of completion of the company's business. In this sense, the performance evaluation is related to whether the company has completed the development goals. So this study from the procedure of company reform, make full use of its resources, and adopt advanced management experience and ideas, basic and complete the transformation process, finally the BPR of performance evaluation, inspection company to complete the process reengineering established strategic planning level. This study focuses on the analysis and evaluation of the results of the performance evaluation in order to provide the basis for the decision of the company leaders and managers.

\section{Reasons and Conditions of Process Reengineering}

The concept of "division of labor" put forward by Adam Simy has produced epoch-making significance in the history of production and greatly improved the productivity of labor. This "division of labor" concept was later be used for automobile production, the complex assembly process is decomposed into a series of simple and easy operation procedures, thereby greatly reducing the automobile production time, reduces the automobile production cost. However, after the improvement of the production efficiency, the problem of production management is brought forward. Therefore, the 
concept of "division of labor" is applied to the management of automobile production. Production and management of the two major aspects of the progress and improvement of automobile production has brought a large-scale development of the times.

Until the end of the last century, the concept of "division of labor" was over used to start to show. The process of labor is too refined to increase the workload and management difficulties, while the process of decomposition and refinement in the process of the combination of more and more complex, resulting in the slow and inefficient workflow. This will inevitably bring the company's strategic objectives difficult to complete and difficult to meet customer needs. In addition, with the pace of economic and cultural globalization in twenty-first Century, the rapid development of technology, the development of the company's business situation is also facing changes. These require the company to develop with the times, according to the changing business environment to transform their business. The study found that in the many factors that affect the development of the company, customer, competition, change is the main factor affecting the development of the company. Therefore, in order to maintain an invincible position in today's competitive environment, it is very important to grasp these three elements.

(1) Customers: with the continuous improvement of living conditions and the material life of the rich, more and more customer needs change, personality, these are the development of the company put forward new challenges. The key to the development of the company is to meet the needs of customers, so retaining customers become the key to the development of the company.

(2) Competition: in the context of globalization, the development of the company is facing competition and challenges from all over the world.

(3) Change: in this rapidly changing era, the needs of customers are changing, the company's living environment is also changing, and these various uncertainties become the key to the smooth development of the company. In order to improve production efficiency and management efficiency, increase operating profit, the company must be reasonable control business operation procedures, business process reengineering.

\section{Establishment of Performance Evaluation Index System of Process Reengineering}

The ever-changing customer demand and the increasingly harsh competition environment forced the company to carry out business process reengineering, build their own core competitiveness. But how to measure the performance of the process reengineering has become another problem in the management of the company. If we cannot accurately determine the effect of implementation, it is difficult to implement the problems in the implementation of feedback and improvement, without effective feedback and improvement, the implementation of process reengineering will become meaningless and role. So it is very important to improve the performance evaluation index system.

(1) The principle of establishing the performance evaluation index system of process reengineering

To establish a sound performance evaluation index system, we must abide by certain criteria, so as to make the performance evaluation system for the company managers to provide accurate information, timely and correct feedback and improvement. These guidelines include:

Scientific rationality. The requirements of the performance evaluation indicators can be included in the implementation of each aspect of the process reengineering, at all levels, to fully reflect the core idea of process reengineering. Among them, we should pay more attention to the mathematical analysis and the calculation method.

Systematicness. The core idea is that the design of the index system should be based on the whole, that is, the emphasis of the process reengineering and the overall balance.

Importance. Its core idea is to focus on the tilt. Different degrees of importance should be used to evaluate the different degree of attention. This can not only improve the efficiency of performance evaluation can also simplify the operation, clear objectives.

Benefit type. The purpose of the operation of all companies are profitable, so in the design of the index system, considering the benefits of the company's operations is a must.

Dynamic property. Everything is developing and changing, and the company is no exception. Customer needs, competitive environment, technological innovation, the concept of managers and so on 
are constantly changing, so the evaluation system should be based on the actual situation to make judgments and changes.

Generality. The design of the evaluation system should have the commonality and universality of the development of things, so that a similar situation can react quickly and take measures.

(2) The specific input and output indicators of process reengineering performance evaluation

There is a close relationship between enterprise process reengineering and enterprise resource support system, capability system and internal support system. The basic purpose of BPR is to improve the competitive advantage and realize the strategic goal of the enterprise. To achieve this goal, it is necessary to decompose the overall strategy into a number of specific objectives to implement. Through the redesign of the operation process of the enterprise, we can reduce the cost, improve the quality, improve the service and improve the speed.

Performance evaluation can be used as an analytical tool for data envelopment analysis. In the input, business process reengineering including funds, personnel, time, and the output can be used to measure the BPR two elements of benefit and efficiency of the numerical value, the specific variables calculated by function method.

The data envelopment analysis for weight distribution of input and output index is not reasonable, therefore, the research in view of the current status of enterprise process reengineering performance evaluation, put forward a cross evaluation hybrid process performance analysis and data envelopment analysis model based on ahp. First of all, all decision making units are combined into a set, and the comparative judgment matrix is constructed by data envelopment analysis. Then the feature vector is calculated by the analytic hierarchy process (AHP), and the weight of the decision making unit is sorted.

Because the analytic hierarchy process is more objective, it can avoid the subjective error of the index of business process reengineering. The cross performance evaluation model based on Data Envelopment Analysis analysis and AHP method can help enterprises to find the weak link in the business process and value links, improve process performance, and coordinate the relationship between enterprise strategic goals and business objectives, through process reengineering to push forward the continuous development of enterprises.

\section{Acknowledgement}

This work was supported by the planning project on culture and art of Jiangxi province (YG2016034).

\section{References}

[1] M.Hammer, James Champy. Re-engineering the corporation: a manifesto for business. Harpoer collins publishers INC, 1993

[2] Evans, Hugh, et al. Exploiting activity. Based information: easy as ABC. Management accounting. 2006, 74(7):24-29.

[3] Fredrik Persson, Jan Olhager. Performance simulation of supply chain designs. Journal of international production economics.2002, 77(9): 231-245. 